\title{
Correction to: TAMSAT
}

Ross Maidment, Emily Black, Helen Greatrex, and Matthew Young

\section{Correction to:}

Chapter 22 in: V. Levizzani et al. (eds.), Satellite Precipitation

Measurement, Advances in Global Change Research 67, https://doi.org/10.1007/978-3-030-24568-9_22

Chapter 22, “TAMSAT” was previously published non-open access. It has now been changed to open access under a CC BY 4.0 license and the copyright holder updated to 'The Author(s)'. The book has also been updated with this change. 